\title{
Effect of Landslide Factor Combinations on the Prediction Accuracy of Landslide Susceptibility Maps in the Blue Nile Gorge of Central Ethiopia
}

\author{
Matebie Meten*, Netra PrakashBhandary and Ryuichi Yatabe
}

\begin{abstract}
Database construction for landslide factors (slope, aspect, profile curvature, plan curvature, lithology, land use, distance from lineament \& distance from river) and landslide inventory map is an important step in landslide susceptibility modelling. Using the frequency ratio model, the weights for each factor classes were calculated and assigned in GIS so as to add these factors and produce landslide susceptibility index maps based on mathematical combination theory. However, before combining them, their independence among each other should be ascertained. For this, the correlation matrix of logistic regression was applied and this showed that most of the correlations between factors were either absent or very insignificant suggesting that all landslide factors are independent. From a set of eight landslide factors, a total of 247 landslide susceptibility map combinations can be generated. However, for simplification, only 28 landslide susceptibility maps were chosen. Then the best landslide susceptibility map was selected based on high prediction accuracy. But, when there is similarity in the prediction accuracies of different combinations, the landslide susceptibility index difference values can be used as another selection criterion. Hence, the susceptibility map from a combination of all landslide factors except distance from river was found to be the best one. Among the 28 representative combinations, landslide susceptibility maps with the same prediction accuracy of $87.7 \%$ have been found in spite of their dissimilarity in their difference values. The combination, with a limited number of landslide factors and the highest prediction accuracy of $87.7 \%$, was found from a combination of slope, lithology, land use and distance from lineament. In order to validate the prediction model, landslides were overlaid over the landslide susceptibility map and the number of landslides that fall into each susceptibility class was calculated. From this analysis $0.39 \%, 1.84 \%, 9.1 \%, 32.04 \%$ and $56.63 \%$ of the landslides fall in the very low, low, medium, high and very high landslide susceptibility classes respectively. Since $88.67 \%$ of the landslides fall in the high and very high susceptibility classes, the landslide susceptibility map can be considered reliable to predict future landslides.
\end{abstract}

Keywords: Landslide susceptibility; GIS; Frequency ratio; Combination; Prediction accuracy; Ethiopia

\section{Background}

Landslide is the movement of a mass of rock, debris or earth (soil) down a slope and landslide susceptibility is a quantitative or qualitative assessment of landslide about its classification, volume (or area) and spatial distribution (IUGS 1997, Fell et al. 2008). Landslide susceptibility mapping methods are classified into heuristic (Ruff and Czurda 2008), statistical (Lee et al. 2004; Pradhan et al.

\footnotetext{
* Correspondence: matebe21@gmail.com

Geo-Disaster Research Laboratory, Graduate School of Science and Engineering, Ehime University, 3 Bunkyo, Matsuyama 790-8577, Japan
}

2011), deterministic (Godt et al. 2008) and a combination of statistical and deterministic (Terlien 1998) methods. Susceptibility, hazard and risk maps are important tools for engineers, earth scientists, planners and decision makers select appropriate sites for agriculture, construction and other development activities (Ercanoglu and Gokceoglu 2002). They also play an important role in efforts to mitigate or prevent the disaster in landslide prone areas by providing important information to the concerned bodies. In heuristic methods, field observation and expert's knowledge are used to identify landslides, 
make a prior assumption about past and future landslide movements on the site, assign weighted values for the classes of index maps and overlay them to produce a landslide susceptibility map. In deterministic method, data on slope geometry, shear strength (cohesion and angle of internal friction) and pore pressure are required (Regmi et al. 2010a). A significant limitation of deterministic models is the need for geotechnical data (cohesion, internal angle of friction, depth to groundwater table, degree of saturation etc.) which are difficult to obtain over large areas (Terlien et al. 1995).

Data from Ayalew (1999), Temesgen et al. (2001), Woldearegay (2008) and Ibrahim (Ibrahim J, 2011: Landslide assessment and hazard zonation in Mersa and Wurgessa, North Wollo, Ethiopia, unpublished Master Thesis) showed that landslide in Ethiopia has resulted loss of human lives, properties and infrastructures particularly in the last five decades. From 1960 to 2010 alone, about 388 people were dead, 24 people were injured and a great deal of agricultural lands, houses and infrastructures were affected. Landslide problem in the Abay (Blue Nile) Gorge is a serious challenge to the community residing in this area and to the road infrastructure that connects Addis Ababa to Bahir Dar. In 1960, a terrible landslide at Gembechi village within Bechet valley was responsible for the loss of 45 people (Ayalew 1999). On September 2, 1993 a landslide incidence occurred in the Blue Nile Gorge, which killed an ox, damaged agricultural fields, destroyed crops and as a result 700 households were stricken by food insecurity. Besides this the main road, which was $5 \mathrm{~km}$ south of Dejen town has been damaged with a displacement of 1.5 meters by the sliding mass (Tadesse T, Dessie $\mathrm{T}$ and Deresa $\mathrm{K}$, 1994: Landslide incidence in the Blue Nile Gorge of East Gojam, Ethiopia. Geological Survey of Ethiopia, 823 report, 830-301-01, unpublished). The road damage is a common phenomenon of the mid to end of each rainy season (i.e. June 1 to September 30) due to the gradual weakening of the soft and weathered rocks by heavy rain and groundwater percolation through big columnar joints of basalt to the underlying limestone formation bearing mudstone and shale at its top and middle strata. For example, Asfaw (2010) reported a road damage near Goha Tsiyon town on September 5, 2009. Such incidences happened due to the progressive softening of weathered basalt and pyroclastic rocks by heavy rainfall, groundwater recharge through the columnar joints of basalt and by a gushing stream that crosses a road. The Goha Tsion-Dejen transect is an important transport corridor connecting Addis Ababa with the regions in the northwestern part of the country. However, it is affected by a complex landslide problem almost on a yearly basis. To overcome this problem, few researchers in the field of Geotechnics, Geoscience and slope stability have been undertaking investigations in the Blue Nile Gorge. Recently, GIS is becoming a powerful tool to study landslide susceptibility and hazard worldwide because of its analysis potential and capability. A continuous and up to date landslide susceptibility map is vital to planners, engineers and decision makers in order to devise appropriate landslide prevention and mitigation measures. In this regard, a statistical (probabilistic) model known as frequency ratio has been applied in the current study area. This model was chosen because it is easy to understand and simple to implement. Data input, output and analysis processes are fast and a huge amount of data can be handled and run quickly (Lee and Pradhan 2007; Lee et al. 2007).

Frequency ratio model avoids the lengthy procedures of raster to point data conversion in GIS, weight calculation in statistical software and switching from statistical software to GIS for the preparation of landslide susceptibility map unlike logistic regression and artificail neural network models. Besides this, it utilizes all the available data contrary to the other two models, which may use a limited proportion of the data because of the low data processing capacity of the statistical software. Using a frequency ratio model, Lee and Talib (2005) have found the prediction accuracy of $72.1 \%$ in Penang, Malaysia and Lee and Sambath (2006) have found a prediction accuracy of $86.97 \%$ in the Damrei Romel area of Cambodia. Lee and Pradhan (2007) have shown that the frequency ratio resulted a better prediction accuracy than the logistic regression at Selangor area in Malaysia. Similarly, Pradhan (2010a) showed that the validation result of the frequency ratio model in the Cameron catchment of Malaysia is slightly better than logistic regression and fuzzy logic models with a prediction accuracy of $89.25 \%$.

Until now researchers, who were engaged in the this model, were simply summing all the frequency ratio raster maps of landslide factors (Lee and Sambath 2006) or exclude one factor and sum all the remaining ones (Lee and Talib 2005). However, the previous works lack ways of systematic combination, identifying the number of possible combinations, providing more than one selection criterion to select the best landslide susceptibility map and finding a combination with high prediction accuracy from a limited number of factors.

The current study tries to prepare different landslide susceptibility maps from eight landslide factors and landslide inventory with different combinations using frequency ratio model and make a comparison on the prediction accuracies of these combinations in order to select the best landslide susceptibility map. This will help to suggest a limited number of landslide factors that can produce a susceptibility map with the highest prediction accuracy similar to a combination using all or most of the landslide factors. The main objectives of this study are: (1) to apply the frequency ratio model using combination theory, (2) to identify the possible numbers of combinations, (3) to evaluate the effect of different combinations on the prediction accuracy of landslide susceptibility maps and (4) to select the best 
landslide susceptibility map among different alternatives. In light of this, the following questions will be addressed in the subsequent chapters of this paper. (1) How many combinations are possible in the frequency ratio model with a certain number of landslide factors? (2) Which combination of landslide factors will give the best prediction accuracy? (3) How can we prioritize if the two landslide susceptibility maps have the same prediction accuracy? (4) How can we identify the best landslide susceptibility map obtained from a limited number of landslide factors?

\section{Study area}

The study area is located in the Abay (Blue Nile) Gorge of Central Ethiopia and it is bounded by $38^{\circ} 2^{\prime} \mathrm{E}$ to $38^{\circ} 15^{\prime \prime}$ E longitudes and $10^{\circ} 0^{\prime} \mathrm{N}$ to $10^{\circ} 15^{\prime} \mathrm{N}$ latitudes covering an area of 391 sq. km (Figure 1). This area is found in the highly dissected portion of the Blue Nile basin with a depth of $1.5 \mathrm{~km}$ from plateau top to the valley floor. The lowest elevation in the study area is $1000 \mathrm{~m}$ while the highest is $2500 \mathrm{~m}$. It contains the major Abay (Blue Nile) River and its tributary rivers like Bechet, Muga and other unnamed small streams (Figure 2) with the level of incision being higher in the three rivers.

\section{Methods}

The methods applied in this paper include data preparation, data analysis through frequency ratio model, prediction, landslide susceptibility map preparation and validation stages (Figure 3). During the data preparation stage a database was constructed for landslide factor maps and landslide inventory map. The landslide factor maps were derived from the geological map for lithology and lineament, topographic maps for rivers, Google earth images for land use, DEM (digital elevation model) for slope, aspect, profile curvature and plan curvature. The river and lineament data were changed into distance from river and lineament based on Arc GIS multiple ring buffer analysis. The landslide inventory map, which contains 595 landslides, was also prepared from field observation and Google earth image analysis. The continuous data like slope, aspect, profile curvature and plan curvature were reclassified into appropriate number of classes. Then, all the eight landslide factors and landslide inventory map were organized in a raster format with the same geographic projection and same pixel size of $30 \mathrm{~m}$. The frequency ratio model requires assigning the frequency ratio values (FRV) for each factor's class by dividing landslide percentage to area percentage. Then the frequency ratio value maps of landslide factors were added based on the mathematical combination rule in order to get the landslide susceptibility index maps for different combinations. A total of 247 combinations were possible but only 28 best combinations were selected in order to simplify the data handling and analysis process. For prediction purpose the landslide susceptibility index maps were extracted with landslide and non-landslide points and then analyzed using SPSS

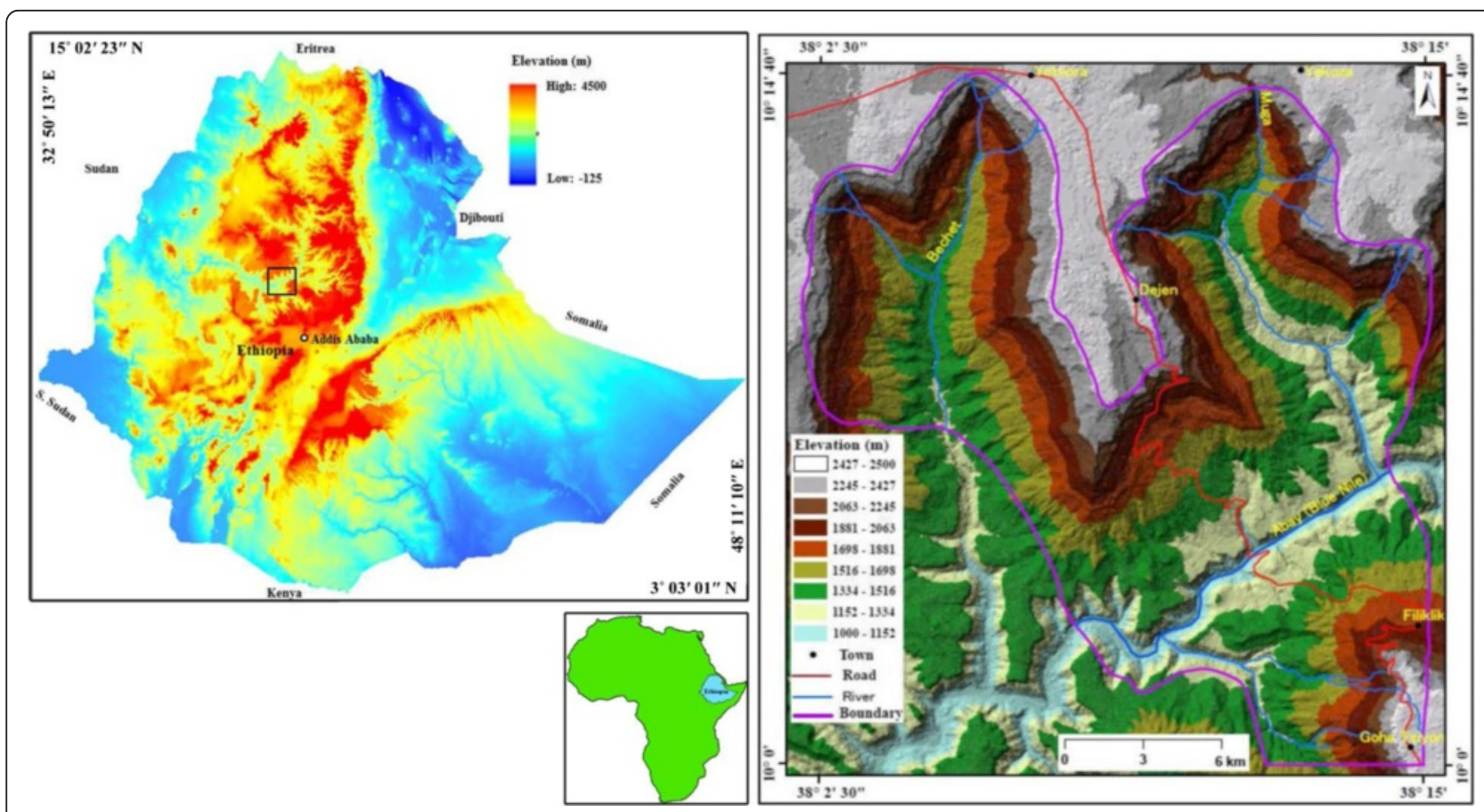

Figure 1 Location map of the study area showing the general landscape and elevation ranges in the Goha Tsiyon-Dejen transect of Abay (Blue Nile) gorge. 


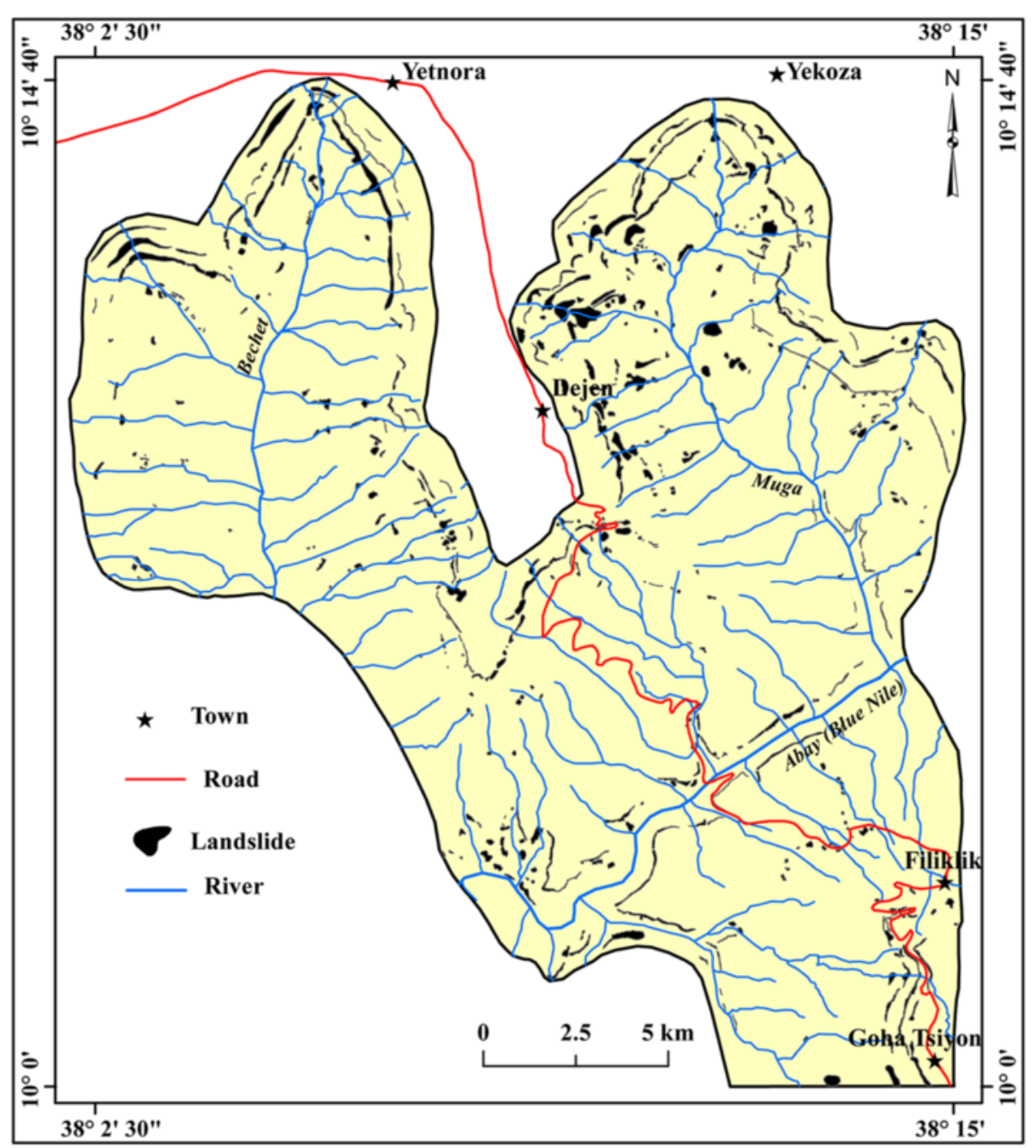

Figure 2 Landslide inventory map of the study area.

statistical software so as to check the overall statistics, receiving operating characteristics (ROC) curves and area under the curve (AUC) values. The prediction accuracies of each combination of landslide factors can be found by multiplying AUC values by $100 \%$. However, the prediction accuracies of different combinations from the success-rate curve may not always be enough to discriminate which landslide susceptibility map is best among many alternatives. Hence, the difference between minimum and maximum landslide susceptibility index (LSI) difference values was also used as another distinguishing criterion. If the difference is higher, then it will be better as it contains a broader range of values compared to the smaller difference values. Based on the highest prediction accuracy and LSI difference values, the best landslide susceptibility map from each combination group or from all combinations was selected. Another optimum landslide susceptibility map with the highest prediction accuracy was also selected from a limited number of landslide factors. Finally, the two landslide susceptibility maps were reclassified into five susceptibility classes and the validation was done by overlaying the landslide inventory map over the best landslide susceptibility map.

\section{Landslide inventory}

A landslide inventory map, consisting 595 landslides, was prepared from field observations and Google earth images of the study area (Figure 2). Landslides in the area include rock slides, rock falls, debris slide and mudflow. According to Ayalew and Yamagishi (2004) rock falls exist as discernible block topples and wedge failures along the mountains, valley walls and road cuts. Similarly, rock slides are also abundant on the ridge sides and valley walls. The intensity of landslides is generally high in the upper catchments of Bechet and Muga valleys and on the road cut near GohaTsiyon town. 


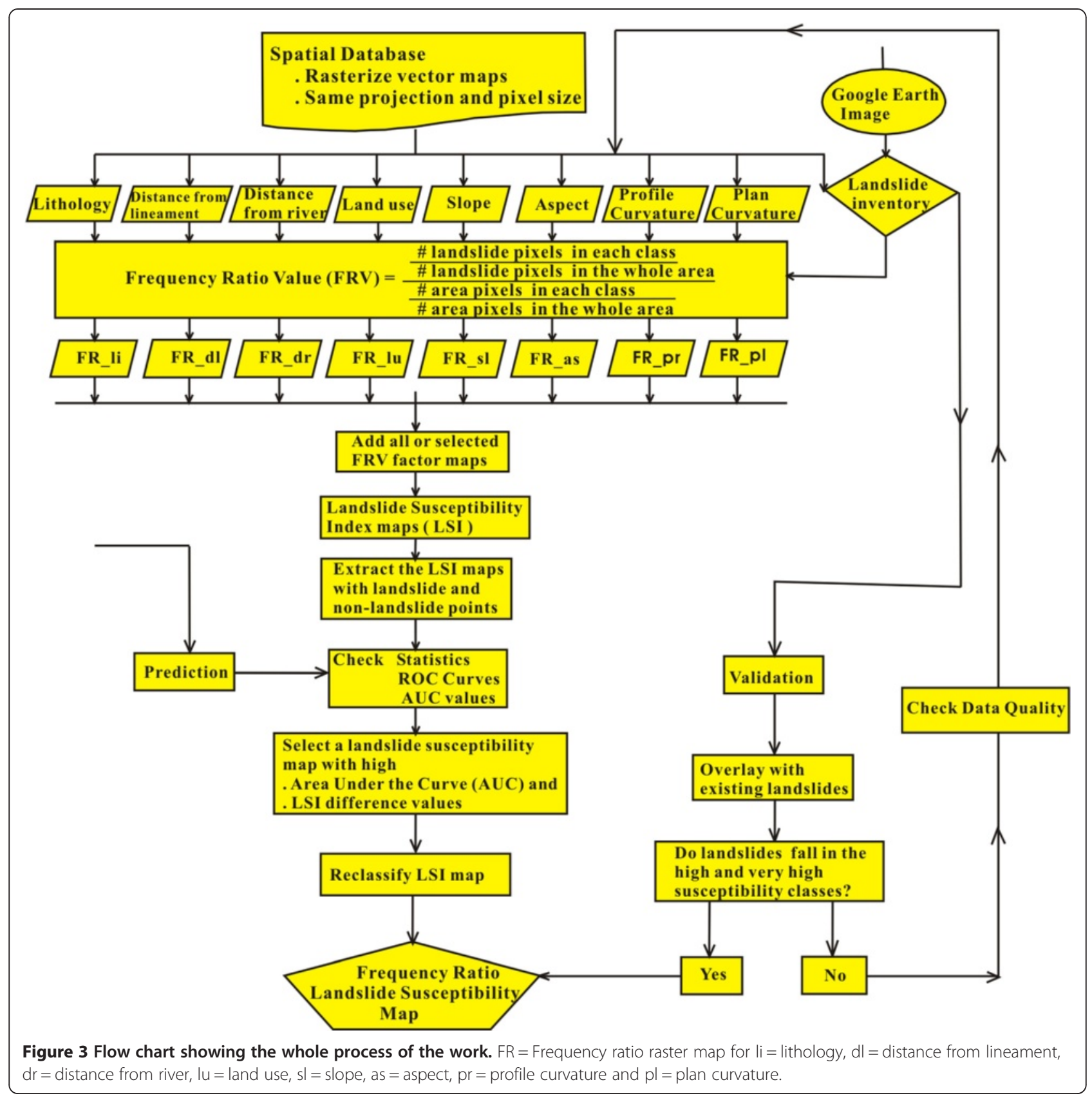

\section{Landslide factors}

The landslide factors used in this paper include lithology, distance from lineament, land use, distance from river, slope, aspect, plan and profile curvatures (Figure 4). The landscapes are greatly influenced by tectonics, bedrock lithology and the courses of major rivers. The complex processes of tectonics, erosion and sedimentation generates water gaps, knick points, meanders and many other tectonic and geomorphic features (Pirasteh et al. 2009). Tectonics may probably promote river incision in one side and river aggradation to the other side and rivers respond in different ways to similar tectonic scenarios. The main effects of tectonics are localized changes in the river course and changes in local topography (Pirasteh et al. 2009).

\section{Lithology}

The lithology of the study area comprises seven lithological units. These are (1) Paleozoic Sandstone (2) Mesozoic Lower Sandstone (3) Mesozoic Gypsum, shale and mudstone (4) Mesozoic Limestone (5) Tertiary Lower Basalt (6) Tertiary Upper Basalt and (7) Quaternary Soil in their chronological order from older to younger units (Figures 5 4e). The Paleozoic Sandstone 


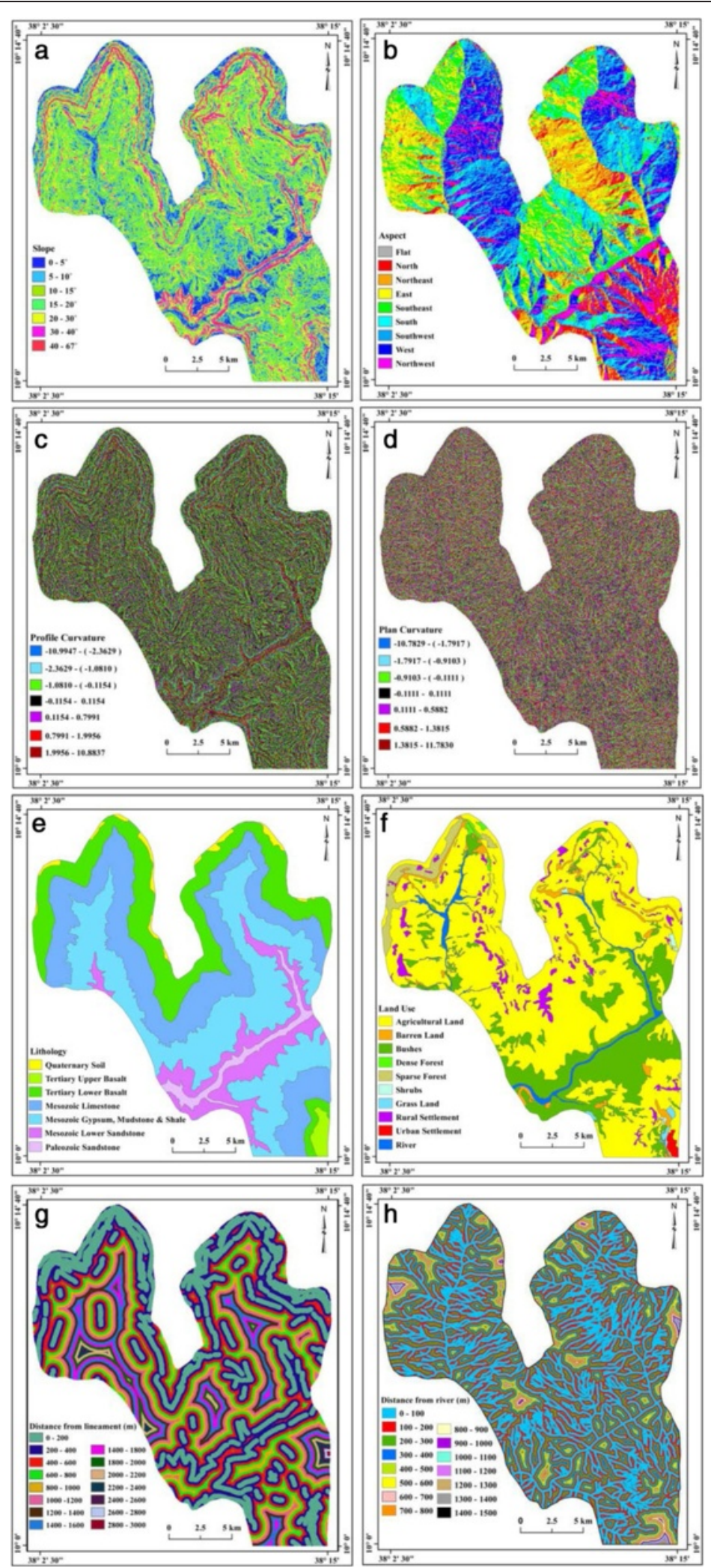

Figure 4 Landslide influencing factors (a) slope (b) aspect (c) profile curvature (d) plan curvature (e) lithology (f) land use (g) distance from lineament $(h)$ distance from river. 


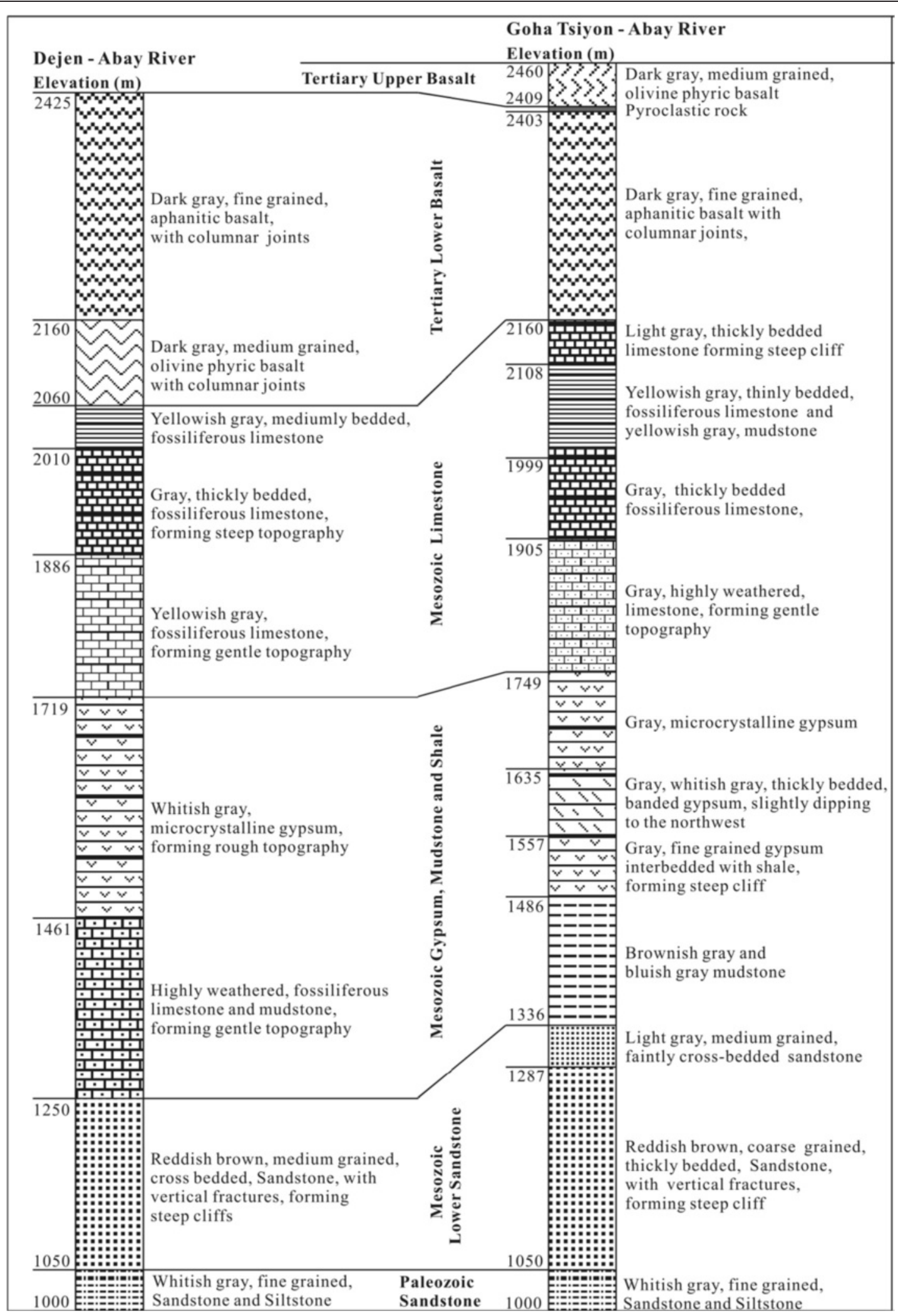

Figure 5 Litho-stratigraphic sections along the GohaTsiyon - Dejen Road. 
consists of fine grained sandstone with whitish gray and brown colors occupying the river course of Abay (Blue Nile) attaining a maximum vertical thickness of $50 \mathrm{~m}$. It is highly weathered, slightly friable forming moderately sloping morphology. Mesozoic Lower Sandstone is reddish brown, light gray, medium to coarse grained, sometimes conglomeratic, medium to thickly bedded and crossbedded sandstone forming steep to moderately sloping cliffs on the river banks of the Abay (Blue Nile) River overlying the Paleozoic Sandstone. This unit is found in elevation range between $1050 \mathrm{~m}$ and $1336 \mathrm{~m}$ with a vertical thickness of $286 \mathrm{~m}$. Mesozoic Gypsum, Mudstone and Shale unit consists of the dominant gypsum interbedded with minor mudstone and shale. This unit is exposed in the elevation range between $1336 \mathrm{~m}$ and $1749 \mathrm{~m}$ in the GohaTsiyon - Abay River section with a vertical thickness of $413 \mathrm{~m}$. Gypsum is whitish gray, gray and sometimes banded, forming gentle morphology. Mudstone is yellowish gray, highly weathered and friable.

Mesozoic Limestone is yellowish gray and light gray in color, mostly fossiliferous, medium to thickly bedded and forms gentle to steep cliffs. The limestone forms a bed thickness of $0.25-0.5 \mathrm{~m}$ and sometimes it may reach up to $1 \mathrm{~m}$. The Tertiary Lower Basalt forms a steep morphology unconformably overlying the Mesozoic Limestone. It is dark gray, fine to medium grained, aphanitic basalt, plagioclase phyric and olivine - plagioclase phyric basalts. The basalt in GohaTsiyon - Dejen Road shows a spectacular columnar jointing and triggers a critical landslide problem. The Tertiary Upper Basalt is dark gray, fine to medium grained rock, consisting plagioclase phyric, olivine phyric and aphanitic basalts overlying thin beds of pyroclastic rocks. Lastly, in-situ weathering of the Tertiary basalts has given rise to the development of Quaternarysoil on the Dejen plateau.

\section{Land Use}

The land use type in the area includes agricultural land, barren land, bushes, dense forest, sparse forest, shrubs, grassland, rural settlement, urban settlement and river (Figure 4f; Table 1). The reason why dense forest, sparse forest and shrubs are susceptible to land sliding can be attributed to the existing steep slope morphology and the sallow rooted nature of different evergreen vegetation types in the area. The presence of vegetation may increase the rate of infiltration. This in turn increases the accumulation of water, thereby decreasing the stability of the slope due to increased pore water pressure and unit weight of the sliding mass (Farrokhnia et al., 2010). This may be worsened if the vegetation types in the area have a huge weight and are shallow rooted with the roots found above the slip surface of the landslide mass. It is obvious that the barren land comprising a degraded portion of the study area which is devoid of any vegetation, particularly on the steep walled river banks of Muga and Bechet rivers, is more highly susceptible to land sliding than the other land use types.

\section{Distance from lineament}

Lineaments, which are found along steep linear ridges in the Abay (Blue Nile) gorge, have a strong influence in conditioning landslide incidences provided that the other favorable factors are also set in place. As can be seen in Table 1, the frequency ratio values for the distance from lineament showed higher values in the distance range of 0 to $200 \mathrm{~m}$. The other distance classes revealed a less number of landslides. The surface rupture intensity is also influenced by distance from lineament or fault and ground conditions. As the distance from the lineaments becomes smaller, the fracture of the rock masses and the degree of weathering increases resulting in greater chances of landslide occurrence (Farrokhnia et al. 2010).

\section{Distance from river}

Rivers usually play a significant role in modifying the landscape by incising the different rocks. In the study area, the Abay (Blue Nile), Bechet and Muga Rivers and many other streams incised the Tertiary Volcanic rocks and Paleozoic and Mesozoic sedimentary rocks to a maximum depth of $1.5 \mathrm{~km}$. The role played by rivers in creating a conducive environment for landslide occurrence has great significance. The maximum number of landslides in the close proximity of rivers, as can be seen in Table 1, shows how rivers are contributing to landsliding. In the steep-walled river banks of Bechet and Muga, landslides are common, particularly in fractured Tertiary Lower Basalt and the underlying Mesozoic Limestone units.

\section{Slope}

Slope is one of the most important topographic parameters influencing the occurrence of landslides in the study area. The landslide frequency is higher in the slope classes of $20-30^{\circ}, 30-40^{\circ}$ and $40-67^{\circ}$ and the highest one is recorded in the slope class of $30-40^{\circ}$ (Table 1 ). Generally speaking, as slope increases, the probability of landslide occurrence also increases.

\section{Aspect}

Aspect (slope orientation) affects the exposure to sunlight, wind and precipitation thereby indirectly affecting other factors that contribute to landslides such as soil moisture, vegetation cover and soil thickness (Clerici et al. 2006). The aspect of the area is classified into flat, north, northeast, east, southeast, south, southwest, west and northwest facing classes (Figure $4 \mathrm{~b}$ ). The number of landslides is higher in the aspect classes of E, SE, S, SW and $\mathrm{W}$ but the frequency ratio values of SE, S and SW 
Table 1 Frequency ratio value calculation by rationing landslide percentage to area percentage

\begin{tabular}{|c|c|c|c|c|c|c|}
\hline Factor & Class & $\begin{array}{l}\text { \# landslide } \\
\text { Pixels }\end{array}$ & $\begin{array}{l}\text { \% landslide } \\
\text { Pixels }^{\mathrm{a}}\end{array}$ & $\begin{array}{l}\# \text { area } \\
\text { Pixels }\end{array}$ & $\begin{array}{l}\% \text { area } \\
\text { Pixels }^{b}\end{array}$ & $\begin{array}{l}\text { FRV = } \\
(a / b)\end{array}$ \\
\hline \multirow[t]{7}{*}{ Slope $\left(^{\circ}\right)$} & $0-5$ & 60 & 0.388 & 38089 & 8.770 & 0.04 \\
\hline & $5-10$ & 333 & 2.151 & 87417 & 20.129 & 0.11 \\
\hline & $10-15$ & 811 & 5.239 & 102933 & 23.702 & 0.22 \\
\hline & $15-20$ & 1430 & 9.238 & 77279 & 17.794 & 0.52 \\
\hline & $20-30$ & 4195 & 27.099 & 80829 & 18.612 & 1.46 \\
\hline & $30-40$ & 4589 & 29.645 & 34095 & 7.851 & 3.78 \\
\hline & $40-67$ & 4062 & 26.240 & 13645 & 3.142 & 8.35 \\
\hline \multirow[t]{9}{*}{ Aspect } & Flat & 5 & 0.03 & 1234 & 0.284 & 0.11 \\
\hline & $\mathrm{N}$ & 424 & 2.74 & 29729 & 6.845 & 0.40 \\
\hline & $\mathrm{NE}$ & 1013 & 6.54 & 44175 & 10.172 & 0.64 \\
\hline & E & 2127 & 13.74 & 64829 & 14.928 & 0.92 \\
\hline & SE & 3136 & 20.26 & 60584 & 13.950 & 1.45 \\
\hline & S & 2306 & 14.90 & 52443 & 12.076 & 1.23 \\
\hline & SW & 3144 & 20.31 & 73195 & 16.854 & 1.21 \\
\hline & W & 2366 & 15.28 & 67137 & 15.459 & 0.99 \\
\hline & NW & 959 & 6.20 & 40961 & 9.432 & 0.66 \\
\hline \multirow[t]{7}{*}{ Plan curvature } & $-10.7829--1.7917$ & 620 & 4.005 & 2810 & 0.647 & 6.19 \\
\hline & $-1.7917--0.9103$ & 1704 & 11.008 & 20924 & 4.818 & 2.28 \\
\hline & $-0.9103--0.1111$ & 4986 & 32.209 & 154198 & 35.506 & 0.91 \\
\hline & $-0.1111-0.1111$ & 1724 & 11.137 & 78020 & 17.965 & 0.62 \\
\hline & $0.1111-0.5882$ & 3117 & 20.136 & 121053 & 27.874 & 0.72 \\
\hline & $0.5882-1.3815$ & 2315 & 14.955 & 49643 & 11.431 & 1.31 \\
\hline & $1.3815-11.7830$ & 1014 & 6.550 & 7639 & 1.759 & 3.72 \\
\hline \multirow[t]{7}{*}{ Profile curvature } & - $10.9947--2.3629$ & 767 & 4.955 & 3648 & 0.840 & 5.90 \\
\hline & $-2.3629--1.0810$ & 1984 & 12.817 & 23076 & 5.314 & 2.41 \\
\hline & $-1.0810--0.1154$ & 4045 & 26.130 & 151550 & 34.896 & 0.75 \\
\hline & $-0.1154-0.1154$ & 1332 & 8.605 & 74725 & 17.206 & 0.50 \\
\hline & $-0.1154-0.7991$ & 3358 & 21.693 & 134940 & 31.072 & 0.70 \\
\hline & $0.7991-1.9956$ & 2737 & 17.681 & 40629 & 9.355 & 1.89 \\
\hline & $1.9956-10.8837$ & 1257 & 8.120 & 5719 & 1.317 & 6.17 \\
\hline Distance from river & $0-100$ & 5975 & 38.60 & 173853 & 40.032 & 0.96 \\
\hline \multirow[t]{12}{*}{ (m) } & $100-200$ & 3728 & 24.08 & 116838 & 26.903 & 0.90 \\
\hline & $200-300$ & 2305 & 14.89 & 63633 & 14.652 & 1.02 \\
\hline & $300-400$ & 1323 & 8.55 & 34376 & 7.916 & 1.08 \\
\hline & $400-500$ & 810 & 5.23 & 19283 & 4.440 & 1.18 \\
\hline & $500-600$ & 480 & 3.10 & 11048 & 2.544 & 1.22 \\
\hline & $600-700$ & 350 & 2.26 & 6352 & 1.463 & 1.55 \\
\hline & $700-800$ & 223 & 1.44 & 3866 & 0.890 & 1.62 \\
\hline & $800-900$ & 102 & 0.66 & 2253 & 0.519 & 1.27 \\
\hline & $900-1000$ & 49 & 0.32 & 1351 & 0.311 & 1.02 \\
\hline & $1000-1100$ & 74 & 0.48 & 748 & 0.172 & 2.78 \\
\hline & $1100-1200$ & 47 & 0.30 & 485 & 0.112 & 2.72 \\
\hline & $1200-1300$ & 14 & 0.09 & 150 & 0.035 & 2.62 \\
\hline
\end{tabular}


Table 1 Frequency ratio value calculation by rationing landslide percentage to area percentage (Continued)

\begin{tabular}{|c|c|c|c|c|c|c|}
\hline & $1300-1400$ & 0 & 0.00 & 46 & 0.011 & 0.00 \\
\hline & $1400-1500$ & 0 & 0.00 & 5 & 0.001 & 0.00 \\
\hline \multirow[t]{2}{*}{ Factor } & Class & \# landslide & $\%$ landslide & \# area & $\%$ area & $\mathrm{FRV}=$ \\
\hline & & Pixels & Pixels ${ }^{a}$ & Pixels & Pixels $^{b}$ & $(\mathrm{a} / \mathrm{b})$ \\
\hline Distance from & $0-200$ & 11297 & 72.978 & 108715 & 25.033 & 2.92 \\
\hline \multirow[t]{14}{*}{ Lineament (m) } & $200-400$ & 2017 & 13.030 & 84627 & 19.486 & 0.67 \\
\hline & $400-600$ & 930 & 6.008 & 61629 & 14.191 & 0.42 \\
\hline & $600-800$ & 487 & 3.146 & 47825 & 11.012 & 0.29 \\
\hline & $800-1000$ & 236 & 1.525 & 36076 & 8.307 & 0.18 \\
\hline & $1000-1200$ & 169 & 1.092 & 26915 & 6.198 & 0.18 \\
\hline & $1200-1400$ & 175 & 1.130 & 23374 & 5.382 & 0.21 \\
\hline & $1400-1600$ & 119 & 0.769 & 18887 & 4.349 & 0.18 \\
\hline & $1600-1800$ & 42 & 0.271 & 12387 & 2.852 & 0.10 \\
\hline & $1800-2000$ & 6 & 0.039 & 7334 & 1.689 & 0.02 \\
\hline & $2000-2200$ & 2 & 0.013 & 3926 & 0.904 & 0.01 \\
\hline & $2200-2400$ & 0 & 0.000 & 1634 & 0.376 & 0.00 \\
\hline & $2400-2600$ & 0 & 0.000 & 576 & 0.133 & 0.00 \\
\hline & $2600-2800$ & 0 & 0.000 & 281 & 0.065 & 0.00 \\
\hline & $2800-3000$ & 0 & 0.000 & 101 & 0.023 & 0.00 \\
\hline \multirow[t]{10}{*}{ Land use } & Agricultural land & 7518 & 48.566 & 290914 & 66.987 & 0.725 \\
\hline & Sparse forest & 706 & 4.561 & 10747 & 2.475 & 1.843 \\
\hline & Rural settlement & 55 & 0.355 & 16384 & 3.773 & 0.094 \\
\hline & Barren land & 4085 & 26.389 & 12423 & 2.861 & 9.225 \\
\hline & Bushes & 2813 & 18.172 & 88635 & 20.409 & 0.890 \\
\hline & River & 0 & 0 & 10049 & 2.314 & 0 \\
\hline & Dense forest & 171 & 1.105 & 1347 & 0.310 & 3.562 \\
\hline & Grass land & 39 & 0.252 & 1357 & 0.312 & 0.806 \\
\hline & Shrubs & 93 & 0.601 & 999 & 0.230 & 2.612 \\
\hline & Urban settlement & 0 & 0 & 1432 & 0.330 & 0 \\
\hline \multirow[t]{7}{*}{ Lithology } & Quaternary soil & 184 & 1.189 & 6221 & 1.432 & 0.83 \\
\hline & Tertiary lower basalt & 7733 & 49.955 & 94821 & 21.834 & 2.29 \\
\hline & Mesozoic limestone & 4011 & 25.911 & 129156 & 29.740 & 0.87 \\
\hline & Mesozoic gypsum, Mudstone and shale & 1170 & 7.558 & 140797 & 32.420 & 0.23 \\
\hline & Mesozoic lower sandstone & 2086 & 13.475 & 46758 & 10.767 & 1.25 \\
\hline & Paleozoic sandstone & 55 & 0.355 & 12044 & 2.773 & 0.13 \\
\hline & Tertiary upper basalt & 241 & 1.557 & 4490 & 1.034 & 1.51 \\
\hline
\end{tabular}

facing slopes were found to be significant in causing landslides.

Profile and plan curvatures

Profile and plan curvatures are used for hill-slope and landslide analysis (Ayalew and Yamagishi 2004). (Ohlamacher 2007) presented a detailed account of plan curvature and its effect on hill-slope stability in earth flow and earth slides dominated regions. Plan curvature is the curvature of the topographic contours or the curvature of a line formed by the intersection of an imaginary horizontal plane with the ground surface. Hillsides can be concave outward plan curvatures called hollows, convex outward plan curvatures called noses and straight contours called planar regions. In hollows landslide material converges into the narrow region at the base of the slope. Profile curvature is the curvature in the downslope direction along a line formed by the 
intersection of an imaginary vertical plane with the ground surface (Ohlamacher 2007). Both profile and plan curvatures affect the susceptibility to landslides. Profile curvature affects the driving and resisting stresses within a landslide in the direction of motion. Plan curvature controls the convergence or divergence of landslide material and water in the direction of landslide motion (Carson and Kirkby 1972). The sign of the curvature value is important for determining concavity or convexity of the curve. In both profile and plan curvature maps, concave and convex surfaces are represented by the respective negative and positive values (Pradhan 2010a). Based on the plan curvature hill-slopes can be subdivided into hollows, noses and relatively planar regions. Hollows are regions in which the plan curvature of the contours is concave in the downslope direction and where surface water would converge as it moves downslope (Reneau and Dietrich 1987). Noses or coves are regions where the plan curvature of the contours is convex in the downslope direction and the surface water will diverge (Hack and Goodlett 1960). Relatively planar regions have plan curvature values around zero. Hollows concentrate groundwater and the concentration of groundwater probably leads to increased landslide activity.

\section{Triggering factor}

The most important triggering factor for landslide occurrence in the Blue Nile Gorge is heavy rainfall from the beginning of June to the end of September. This season accounts for more than $75 \%$ of the annual rainfall in the study area. Data from National Meteorological Agency of Ethiopia showed that the minimum, average and maximum annual rainfalls of the study area are $1100 \mathrm{~mm}, 1200 \mathrm{~mm}$ and $1400 \mathrm{~mm}$ respectively and sometimes the peak annual rainfall reaches up to $1985 \mathrm{~mm}$ (Figure 6a). The peak monthly rainfall in four stations showed its maxima during the months of July and August (Figure 6b). Landslides usually occur at the beginning or mid of September after the soil and rocks are saturated and the pore water pressure becomes high. In every rainy season landslide events are happening along the main national road between Goha Tsiyon and Dejen and also at steeply sloping ridges and steepwalled river banks.

\section{Theory}

\section{Frequency ratio method}

The assumption of conditions that are similar to the past is very important for landslide susceptibility mapping (Lee and Talib 2005). Probabilistic (statistical) approaches are based on relationships between each landslide factor and the distribution of past landslides (Lee and Talib 2005) and this relationship can be evaluated quantitatively using the frequency ratio model. The eight landslide factors that are used in this study include lithology, land use, distance from lineament, distance from river, slope, aspect, profile and plan curvatures were used to establish this relationship with landslides (Table 1).

The number of landslide pixels in each class has been evaluated and the frequency ratio for each factor class is found by dividing the landslide ratio by the area ratio (Lee and Talib 2005). Frequency ratio shows the correlation between landslides and causative factors in a specific area. If this ratio is greater than 1 , then the relationship between a landslide and the factor's class will be strong but if the ratio is less than 1 , then the relationship will be weak and if the value is 1 , it means an average correlation (Lee and Sambath 2006; Pradhan 2010a). Once the frequency ratio of each landslide factor's class was found, the landslide susceptibility index (LSI) can be calculated by summation of each factor's frequency ratio values (Lee and Sambath 2006). A higher LSI means a higher susceptibility to landslide while a lower LSI indicates a lower susceptibility to landslides (Bui et al. 2012).

In the current study, landslide factors were converted into raster maps with a pixel size of $30 \mathrm{~m}$, the spatial relationship between the landslide location and each landslide factor was analyzed and the ratings for each factor's class were assigned to each class in a specific factor. Then the frequency ratio ratings of factors in the form of raster maps were summed to form the landslide susceptibility index (LSI) using equation (1).

$$
\mathrm{LSI}=\sum_{i=1}^{n} F r
$$

Where Fr is the raster map of each landslide factor in which the frequency ratio values (FRV) are assigned to it. The current study tries to analyze the effect of different combinations of landslide factors on the performance of the frequency ratio model in order to get the minimum number of landslide factors which can produce a susceptibility map with higher prediction accuracy similar to combining many landslide factors using the mathematical combination theory.

\section{Mathematical combination theory}

In mathematics, a combination is a way of selecting members from a grouping, such that the order of selection does not matter unlike permutations. In smaller cases it is possible to count the number of combinations. For example, given three fruits, say an apple, an orange and a pear, there are three combinations of two that can be drawn from this set: an apple and a pear; an apple and an orange; or a pear and an orange. More formally, a $k$-combination of a set $S$ is a subset of $k$ distinct elements of $S$. If the set has $n$ elements, the number of $k$ - 


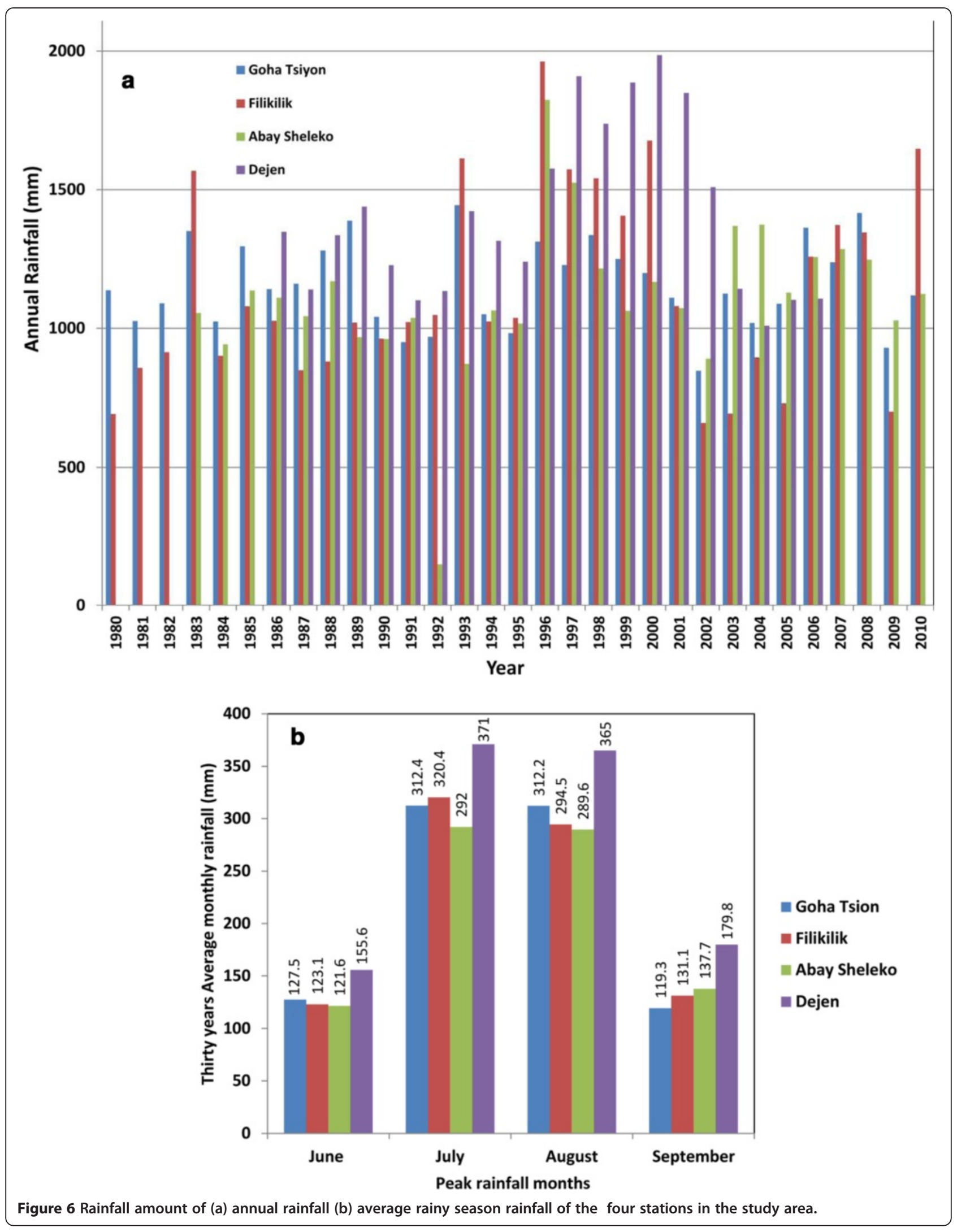


combinations is equal to the binomial coefficient (http:// en.wikipedia.org/wiki/Combination) as follows.

$$
\left(\begin{array}{l}
n \\
k
\end{array}\right)=\frac{n(n-1) \ldots(n-k+1)}{k(k-1) \ldots 1}
$$

This can be written using factorials as:

$$
\frac{n !}{k !(n-k) !}
$$

Where $k \leq n$, and which is zero when $k>n$.

Combinations refer to the combination of $n$ things taken $k$ at a time without repetition.

In combination, the ordering of selected objects is immaterial. The current study applies the combination approach in order to select and combine different number of landslide factors among the eight landslide factors. The possible numbers of combinations of $8,7,6,5$, 4,3 and 2 landslide factors from a set of 8 landslide factors are $1,8,28,56,70,56$ and 28 respectively totaling to 247 possible combinations (Table 2).

\section{Result and discussion}

In order to apply the frequency ratio model, the most important first step is to prepare a database of landslide factors and a landslide inventory map. This involves digitizing polygon features like lithology, land use and landslide inventory; line feature like lineaments and rivers and preparing digital elevation model (DEM) derivatives such as slope, aspect, profile and profile and plan

Table 2 Representative combinations of factors from each group giving the best landslide susceptibility maps using

\begin{tabular}{|c|c|c|c|c|c|c|c|}
\hline No. & $\begin{array}{l}\text { Selected frequency } \\
\text { ration maps }\end{array}$ & $\begin{array}{l}\text { Prediction } \\
\text { accuracy (\%) }\end{array}$ & $\begin{array}{l}\text { \# of landslide } \\
\text { factors used }\end{array}$ & $\begin{array}{l}\text { \# of possible } \\
\text { combinations }\end{array}$ & Min LSI (b) & Max LSI (a) & $\begin{array}{l}\text { Difference } \\
(a-b)\end{array}$ \\
\hline 1 & $\mathrm{sl}+\mathrm{as}+\mathrm{pr}+\mathrm{pl}+\mathrm{li}+\mathrm{lu}+\mathrm{dl}+\mathrm{dr}$ & 87.6 & 8 & 1 & 2.54 & 38.95 & 36.41 \\
\hline 2 & $s \mid+a s+p r+p l+l i+d l+d r$ & 86.2 & 7 & 8 & 2.46 & 29.73 & 27.27 \\
\hline 3 & $s \mid+a s+p r+p l+l i+l u+d l$ & $87.7^{*}$ & & & 1.58 & 36.59 & 35.01 \\
\hline 4 & $s|+p r+p l+l i+| u+d \mid+d r$ & 87.6 & & & 2.37 & 37.74 & 35.37 \\
\hline 5 & $s \mid+a s+p r+p l+l i+l u+d r$ & & & & 2.36 & 36.03 & 33.67 \\
\hline 6 & $s \mid+a s+p r+p l+l u+d l+d r$ & & & & 2.41 & 36.66 & 34.25 \\
\hline 7 & $s|+a s+p l+l i+| u+d \mid+d r$ & $87.7^{*}$ & & & 2.04 & 32.80 & 30.76 \\
\hline 8 & $s l+a s+p r+l i+l u+d l+d r$ & $87.7^{*}$ & & & 1.92 & 32.76 & 30.84 \\
\hline 9 & sl+as+pr+pl+li+lu & 86.9 & 6 & 28 & 1.4 & 33.67 & 32.27 \\
\hline 10 & $\mathrm{sl}+\mathrm{pr}+\mathrm{pl}+\mathrm{li}+\mathrm{dl}+\mathrm{dr}$ & 86.1 & & & 2.29 & 28.70 & 26.41 \\
\hline 11 & $s \mid+a s+p r+p l+l i+d r$ & 84.9 & & & 2.36 & 26.81 & 24.45 \\
\hline 12 & $s \mid+a s+p r+l i+d l+d r$ & 86.3 & & & 1.79 & 23.90 & 22.11 \\
\hline 13 & $s|+a s+l i+| u+d l+d r$ & 87.6 & & & 14.42 & 26.61 & 25.19 \\
\hline 14 & $\mathrm{sl}+\mathrm{pr}+\mathrm{pl}+\mathrm{li}+\mathrm{lu}$ & 86.8 & 5 & 56 & 1.29 & 32.20 & 30.91 \\
\hline 15 & $s \mid+a s+l i+l u+d r$ & 87.0 & & & 1.24 & 23.69 & 22.45 \\
\hline 16 & $s \mid+a s+l i+d l+d r$ & 86.2 & & & 1.28 & 17.79 & 16.51 \\
\hline 17 & $|i+s|+d \mid+d r$ & 86.1 & 4 & 70 & 1.17 & 16.34 & 15.17 \\
\hline 18 & $|i+s|+\mid u+d r$ & 86.8 & & & 1.07 & 22.46 & 21.39 \\
\hline 19 & $|i+s|+p r+l u$ & 87.0 & & & 0.67 & 26.03 & 25.36 \\
\hline 20 & $s \mid+a s+p l+l u$ & 86.4 & & & 0.77 & 25.21 & 24.44 \\
\hline 21 & $s|+| i+\mid u+d l$ & $87.7^{*}$ & & & 0.27 & 22.78 & 22.51 \\
\hline 22 & $s \mid+p l+l i+l u$ & 86.9 & & & 0.79 & 26.05 & 25.56 \\
\hline 23 & sl+as+li & 85.3 & 3 & 56 & 0.28 & 12.09 & 11.81 \\
\hline 24 & $s \mid+d l+l i$ & 86.3 & & & 0.27 & 13.57 & 13.30 \\
\hline 25 & $\mathrm{sl}+\mathrm{as}+\mathrm{dr}$ & 84.7 & & & 1.07 & 13.42 & 12.35 \\
\hline 26 & SI+litlu & 86.9 & & & 0.17 & 19.86 & 19.69 \\
\hline 27 & $|i+s|$ & 85.0 & 2 & 28 & 0.17 & 10.64 & 10.47 \\
\hline 28 & $s l+d r$ & 84.3 & & & 0.04 & 11.13 & 11.09 \\
\hline
\end{tabular}
frequency ratio method

Note: $\mathrm{sl}=$ slope, as=aspect, $\mathrm{pr}=$ profile curvature, $\mathrm{pl}=\mathrm{plan}$ curvature, li=lithology, lu=land use, dl=distance from lineament, dr=distance from river, $\mathrm{LSI}=\mathrm{Landslide}$ Susceptibility Index, ${ }^{*}=$ Highest prediction accuracy. $a=$ Max LSI = maximum landslide susceptibility index, $b=$ Min LSI = minimum landslide susceptibility index. 
curvatures in Arc GIS 10. The distance from lineament and distance from rivers are obtained from multiple ring buffering operation. Then all the data should be transformed into a raster format with the same geographic projection and pixel size $(30 \mathrm{~m})$. The frequency ratio model was applied to obtain a weight for each class in a certain factor. From the frequency ratio analysis, slope classes $\geq 20^{\circ}$ have shown a strong correlation with landslides. In case of aspect, the southeast, south and southwest facing slopes showed a strong correlation with landslides. For profile and plan curvatures, the higher positive values and the lower negative values showed a strong relationship with landslides. Distance from lineament and landslides showed a strong relationship. As the distance from lineament decreases, the frequency ratio values become higher. In a the distance class of 0-200 m, the highest landslide frequency is recorded. From land use classes, barren land, sparse forest and grassland classes showed a strong relation with landslides. Among lithologic units in the area, Mesozoic Lower Sandstone, Tertiary Lower Basalt and Tertiary Upper Basalt showed a strong relationship with landslides. The frequency ratio values were assigned to each factor classes and all these raster maps of landslide factors were added to produce the landslide susceptibility index maps based on the mathematical combination theory.

The frequency ratio model has some limitations despite its easiness and simplicity to understand and implement in a GIS environment. Higher frequency ratio values will be found if the area ratio (area percentage) is lower than the landslide ratio (landslide percentage) irrespective of higher number of landslides in a certain factor class. After the frequency ratio raster maps of all the landslide factors are prepared, the next step is to add these raster maps based on the mathematical combination theory. However, before combining the landslide factors it is important to ascertain their independence from each other (Van Westen et al. 2003, Dahal et al. 2008). For this purpose logistic regression was applied, although the pairwise comparison was preferred by many researchers (Dahal et al. 2008, Regmi et al. 2010a). In this study, the raster maps of the frequency ratio values for the eight landslide factors were extracted with landslide and non-landslide points. These are processed in SPSS statistical software in such a way that landslide represents the presence (1) and non-landslide the absence (0) and each factor's frequency ratio values were analyzed by binary logistic regression in order to check the degree of correlation among landslide factors. Based on this analysis, all the correlations between two different landslide factors showed either no or very insignificant correlation i.e. $<0.1$ (Table 3). This suggests that all the factors are independent from each other and can be used for the combination to prepare a landslide susceptibility map.

From the set of eight landslide factor maps, 8, 7, 6, 5, 4, 3 and 2 factor maps are combined to give 1, 8, 28, 56, 70,56 and 28 landslide susceptibility maps respectively. For simplification, however, only a total of 28 landslide susceptibility index maps have been selected. Then the best landslide susceptibility index map was selected from groups with 8, 7, 6, 5, 4, 3 and 2 landslide factor combinations based on high prediction accuracies calculated from success-rate curves of areas under the curve (AUC). But when there is similarity in prediction accuracy, the difference of maximum and minimum landslide susceptibility index values has been used (Table 2). Hence the best landslide susceptibility map can be selected from a combination with the highest prediction accuracy and the highest difference values and this map was found from a combination of all landslide factors except distance from river (Figure 7a). Among the 28 representative combinations of different landslide factors, landslide susceptibility maps with the same prediction accuracy of $87.7 \%$ have been found in spite of the dissimilarity in their difference values. The combination with a limited number of landslide factors but having the highest prediction accuracy of $87.7 \%$ was also found from four landslide factors, namely slope, lithology, land use and distance from lineament (Figure 7b). In order to show the prediction accuracy contrasts, seven success-rate curves from

Table 3 Correlation matrix of landslide factors

\begin{tabular}{lllllllll}
\hline & $\begin{array}{l}\text { Distance from } \\
\text { lineament }\end{array}$ & Land use & Slope & Lithology & Aspect & $\begin{array}{l}\text { Plan } \\
\text { curvature }\end{array}$ & $\begin{array}{l}\text { Profile } \\
\text { curvature }\end{array}$ & $\begin{array}{l}\text { Distance } \\
\text { from river }\end{array}$ \\
\hline Distance from lineament & 1 & -0.085 & -0.249 & -0.39 & -0.076 & -0.005 & -0.037 & -0.062 \\
Land use & & 1 & -0.086 & -0.07 & -0.058 & 0.004 & -0.008 & 0.055 \\
Slope & & & 1 & -0.002 & -0.01 & -0.165 & -0.294 & 0.011 \\
Lithology & & & 1 & -0.077 & -0.002 & -0.043 & -0.138 \\
Aspect & & & & 1 & 0.015 & -0.004 & 0.007 \\
Plan curvature & & & & & & -0.336 & 0.005 \\
Profile curvature & & & & & & & 1 & -0.004 \\
Distance from river & & & & & & & & \\
\hline
\end{tabular}




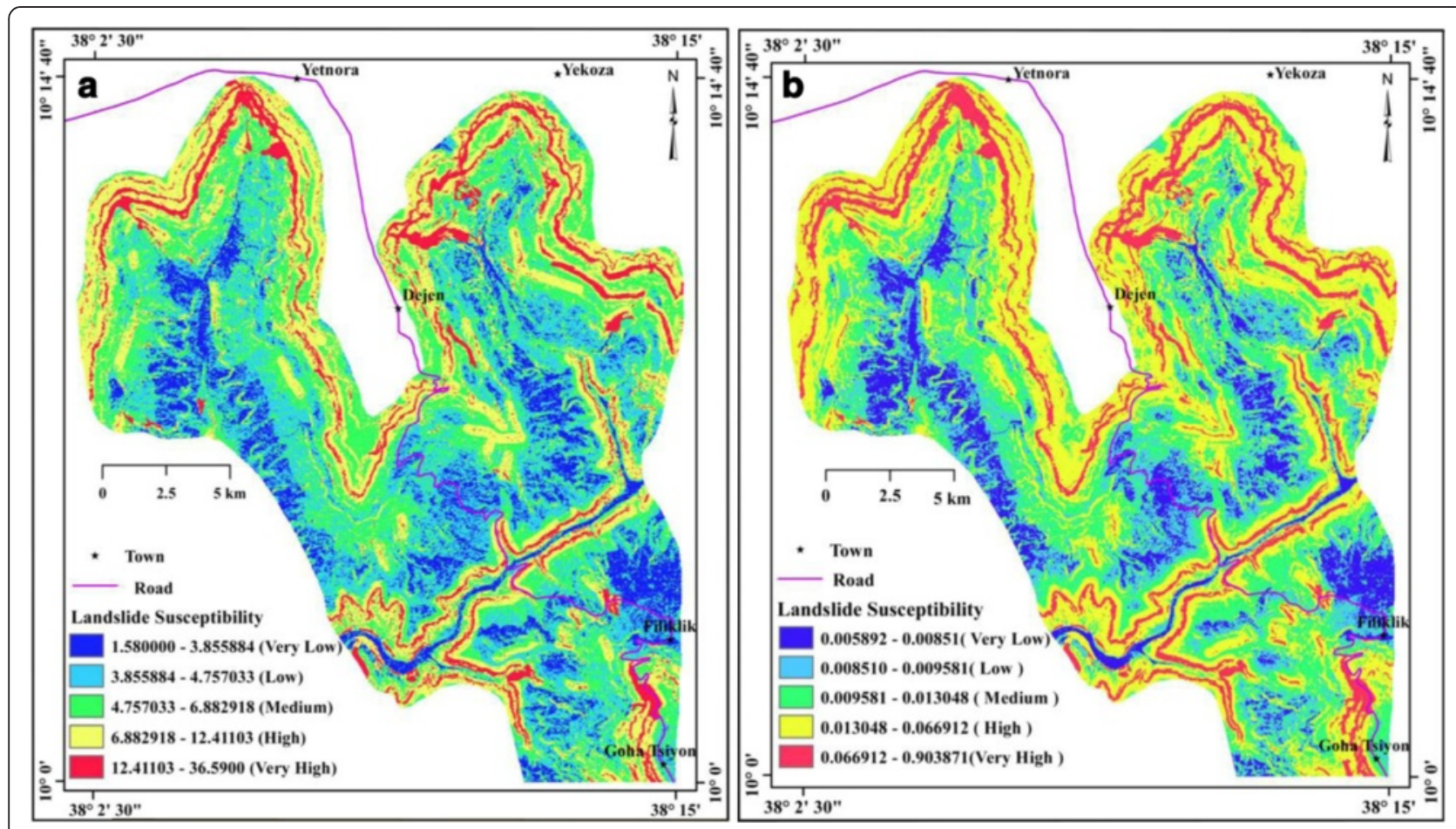

Figure 7 Landslide susceptibility maps having the same prediction accuracy from (a) seven landslide factors excluding distance from river (FR_wo_dr) (b) four landslide factors including slope, lithology, land use and distance from lineament only (FR_ slliludl).

ROC curves were constructed for each group's higher prediction accuracy and difference values (Figure 8).

For validation purpose of landslide susceptibility maps, many researchers divided the landslides in their respective study area into two parts based on time, space and random partitions (Chung and Fabbri 2003). These partitions fall into two categories: prediction (training) landslides and validation (testing) landslides. In time partition, past landslides are classified into landslides that occurred before a certain year X and those that occurred after a certain year X. In space partition, the entire study area is divided into two separate sub areas, A and B, one for prediction and the other for validation. By using the space-partition technique, the prediction model in the study area can be extended into the surrounding areas with similar geology, geomorphology and land use conditions. To know how much the prediction can be extended in space Chi et al. (2002) divided the entire study area into a northern and southern sub-areas because of the area's similarity in many aspects. Lee et al. (2007) divided into western and eastern areas for training and validation purposes respectively. In random partition, the past landslides are randomly divided into two groups instead of two time periods.

However, few researchers advocate for another validation technique which is based on the comparison of existing landslides with the landslide susceptibility map and use the success-rate curve of area under the curve

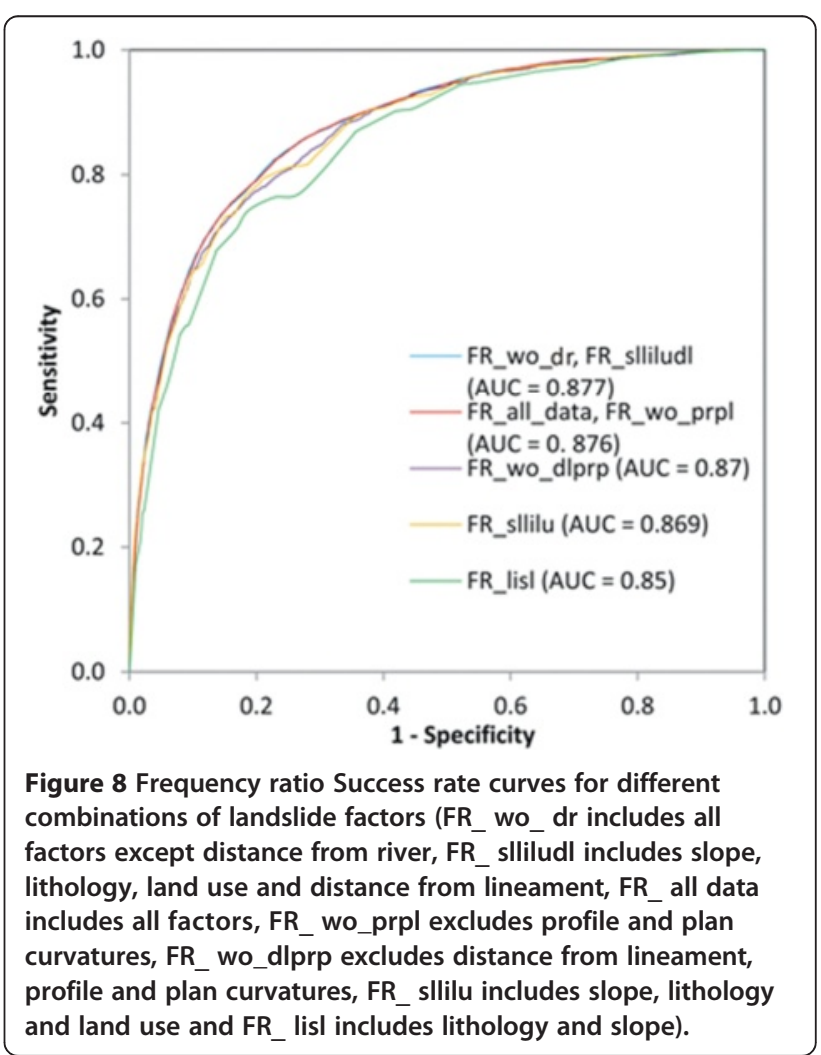


(AUC) to assess the prediction accuracy qualitatively (Lee and Talib 2005; Lee and Sambath 2006; Pradhan 2010a; Pradhan 2011). The success rate curve explains how well the model and the factor predict landslides (Chung and Fabbri 2003) and it was constructed for the representative combinations of seven groups in the study area (Table 2). After an overlay analysis of landslides with the best landslide susceptibility map, the number of landslides that fall into each susceptibility class was calculated. If the number of landslides is very significant in the high and very high susceptibility classes, then the landslide susceptibility map can be considered accurate and reliable to predict future landslides. The prediction accuracy that is used for selection of best susceptibility map was derived from the success - rate curves. In this study, the percentage of landslides in each susceptibility class were calculated to check the validity of the final susceptibility map. For this, all the landslides have been overlaid over the final landslide susceptibility map. In doing so, $0.39 \%, 1.84 \%, 9.1 \%, 32.04 \%$ and $56.63 \%$ of the landslides fall in the very low, low, medium, high and very high landslide susceptibility classes respectively (Figure 9).

\section{Conclusion}

From this study, we have found that the mathematical combination theory is an important technique to identify the possible number of combinations in the frequency ratio model. This paper showed that using all landslide factors in the frequency ratio model may not always result in higher prediction accuracy even though the range of values in the susceptibility index map is higher. For example, the combination of 8 landslide factors results a prediction accuracy of $87.6 \%$, while the combinations of all landslide factors except distance from the river provided an accuracy $87.7 \%$. This shows that distance from river is less important as compared to other factors. But the landslide susceptibility index (LSI) difference value always higher in the combination with higher number of landslide factors. On the other hand, different combinations may result the same and high prediction accuracy. For instance, the combination from seven landslide factors (except distance from river) and the combination from four landslide factors (slope, lithology, land use and distance from lineament) showed the same prediction accuracy of $87.7 \%$. This showed that these four landslide factors should have a greater degree of influence in causing landslides. A prediction accuracy as high as $85 \%$ was also possible from a combination of slope \& lithology only. This demonstrates how these two factors are very much important in causing landslide occurrence. High prediction accuracy \& LSI difference values are used to select the best landslide susceptibility map. By selecting 2 to 8 numbers of landslide factors from a set of 8 landslide factors, a total of 247 landslide susceptibility map combinations are possible. However 28 combinations were selected based on higher prediction accuracy from success rate curves, higher LSI difference values and through visual inspection of output susceptibility maps. An optimum landslide susceptibility map was prepared from four landslide factors (lithology, slope, land use and distance from lineament) while the best landslide susceptibility map was obtained from the combination of 7 landslide factors excluding distance from river (Figure 7a, b). Both maps have the prediction accuracy of $87.7 \%$ but with different LSI difference values of 35.01 and 25.51 respectively. In order to highlight the prediction accuracy contrasts of landslide susceptibility maps from success-rate curves were chosen from the 28 combinations as shown in Table 2.

Once the most important landslide factors are determined in a certain area, then these can be used to scale up the investigation at the regional level using these causative landslide factors. When landslide inventory map is overlaid over the best landslide susceptibility map, most of the landslides fall in the high and very high susceptibility classes accounting for $88.67 \%$ of the

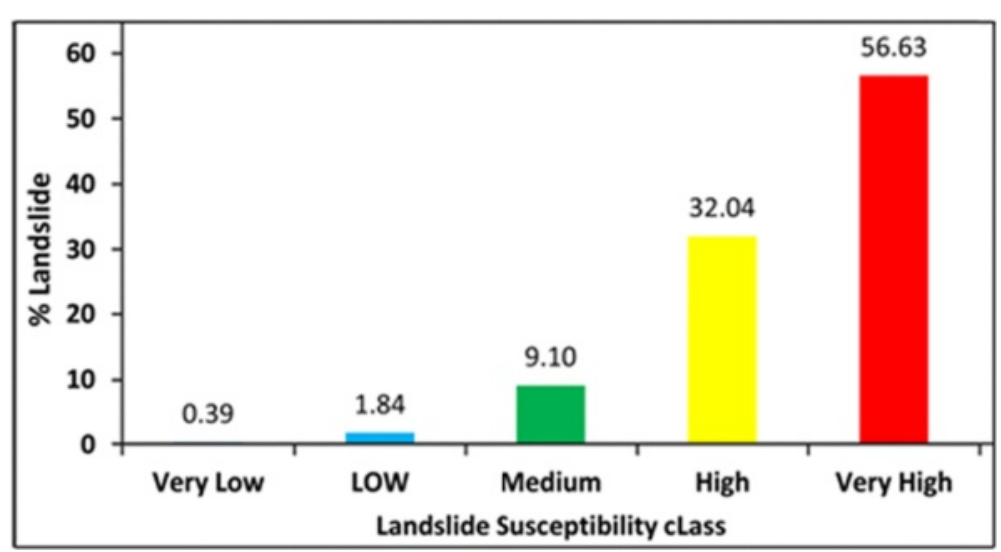

Figure 9 Percentage of Indslides in each landslide susceptibility class for FR_wo_dr. 
landslides. Besides this the success-rate of this map is being $87.7 \%$, proving that the landslide susceptibility map from the frequency ratio model in the study area is quite acceptable. After the best and optimal landslide susceptibility maps (Figure 7 a, b) are selected these maps are divided into five categories and are expressed as probabilities in qualitative terms of very low, low, medium, high and very high susceptibility classes. Using this output, proper planning can be made to prevent, reduce or mitigate the possibility of future landslide disasters in this area. Creating awareness about the risk of high and very high susceptible zones to the general public will help to save the lives and properties of the people. Susceptibility, hazard and risk maps are the basis for decision making usually in the form of technical countermeasures, regulatory measures or combinations of the two (Pradhan et al. 2011).

\section{Competing interests}

The authors declare that we do not have any financial or non-financial competing interests with any individual or institution.

\section{Authors' contributions \\ MM as a first author, has mostly participated in the whole process including field work, data collection, database preparation,compiling the results from himself and from PB, taking comments from RY, address the comments and finalize the draft for journal submission after a consensus is reached with RY and PB. PB has participated from the inception and design of this paper and helped greatly in data preparation and analysis. RY has also involved in a detailed review of the manuscript before submission. Both authors have given the final approval of the version to be published.}

\section{Acknowledgements}

The first author would like to thank Japan's Ministry of Education, Culture, Science and Technology (MEXT) for the scholarship grant to pursue the PhD study.

Received: 26 November 2014 Accepted: 10 February 2015

Published online: 26 March 2015

\section{References}

Asfaw YE (2010) Landslide assessment in the Blue Nile Gorge. University Ghent, Master Thesis, September, Central Ethiopia, 2010

Ayalew $L$ (1999) The effect of seasonal rainfall on landslides in the highlands of Ethiopia. Bull Eng Geol Env 58:9-19, 7 Q Springer-Verlag

Ayalew L, Yamagishi H (2004) Slope failures in the Blue Nile basin, as seen from landscape evolution perspective. Geomorphology 57(2004):95-116

Bui DT, Pradhan B, Lofman O, Revhaug I, Dick OB (2012) Landslide Susceptibility Assessment at Hoa Binh Province of Vietnam Using Frequency Ratio Model. 2012 Asia Pacific Conference on Environmental Science and Technology. Advances in Biomedical Engineering 6:476

Carson MA, Kirkby MJ (1972) Hillslope Form and Process. Cambridge University Press, London, $475 \mathrm{pp}$

Chi KH, Park NW, Chang CJ (2002) Fuzzylogic integration for landslide hazard mapping using spatial data from Boeun, Korea. Symposium on Geospatial Theory, processing and applications, Ottawa

Chung CJF, Fabbri AG (2003) Validation of Spatial Prediction Models for Landslide Hazard Mapping. Nat Hazards 30(451-472):2003

Clerici A, Perego S, Tellini C, Vescovi P (2006) A GIS-based automated procedure for landslide susceptibility mapping by the Conditional Analysis method: the Baganza valley case study (Italian Northern Apennines). Environ Geol 50:941-961, doi:10.1007/s00254-006-0264-7

Dahal RK, Hasegawa S, Nonomura A, Yamanaka M, Dhakal S, Paudyal P (2008) Predictive modelling of rainfall-induced landslide hazard in the Lesser Himalaya ofNepal based on weights-of-evidence. Geomorphology 102:496-510
Ercanoglu M, Gokceoglu C (2002) Assessment of landslide susceptibility for a landslide-prone area (north of Yenice, NW Turkey) by fuzzy approach. Environ Geol 41:720-730, doi:10.1007/s00254-001-0454-2

Farrokhnia A, Pirasteh S, Pradhan B, Pourkermani M and Arian M (2010) A recent scenario of mass wasting and its impact on the transportation on Albroz mountains, Iran using geo-information technology. Arab J Geosci. doi:10.1007/s 12517-010-0238-7

Fell R, Corominas J, Bonnard C, Cascini L, Leroi E, Savage WZ (2008) Guidelines for landslide susceptibility, hazard and risk zoning for land use planning. Eng Geol 102(2008):85-98

Godt JW, Baum RL, Savage WZ, Salciarini D, Schulz WH, Harp EL (2008) Transient deterministic shallow landslide modeling, Requirements for susceptibility and hazard assessments in a GIS framework. Eng Geol 102:214-226

Hack JT, Goodlett JC (1960) Geomorphology and forest ecology of a mountain region in the central Appalachians. United States Geological Survey, Professional Paper 347:66

IUGS (1997) Quantitative risk assessment for slopes and landslides- the state of the art. In: Cruden D, Fell R (eds) Landslide risk assessment. Balkema, Rotterdam, pp 3-12

Lee S, Pradhan B (2007) Landslide Hazard mapping at Selangor, Malaysia using frequency ratio and logistic regression model. Landslides 4:33-41, doi:10.1007/s10346-006-0047-y

Lee S, Sambath T (2006) Landslide susceptibility mapping in the Damrei Romel area, Cambodia using frequency ratio and logistic regression models. Environ Geol 50:847-855, doi:10.1007/s00254-006-0256-7

Lee S, Talib JA (2005) Probabilistic landslide susceptibility and factor effect analysis. Environ Geol 47:982-990, doi:10.1007/s00254-005-1228-z

Lee S, Choi J, Woo I (2004) The effect of spatial resolution on the accuracy of landslide susceptibility mapping: a case study in Boun, Korea. Geosci J 8(No. 1):51-60

Lee S, Ryu JH, Kim LS (2007) Landslide susceptibility analysis and its verification using likelihood ratio, logistic regression, and artificial neural network models: case study of Youngin, Korea. Landslides 4:327-338, doi:10.1007/s10346-007-0088-x

Ohlamacher GC (2007) Plan curvature and landslide probability in regions dominated by earth flows and earth slides. Eng Geol 91(2007):117-134

Pirasteh S, Woodbridge K, Rizvis SMA (2009) Geo-information technology (GiT) and tectonic signatures: the River Karun and Dez, Zagros Orogen in south-west Iran. Int J Remote Sens 30(No. 2):389-403

Pradhan B (2010a) Landslide susceptibility mapping of a catchment area using frequency ratio, fuzzy logic and multiple logistic regression approaches. J Indian Soc Remote Sens 38:301-320, Springer

Pradhan B (2011) Manifestations of an advanced fuzzy logic model coupled with Geo-information techniques to landlside susceptibility mapping and their comparison. Environ Ecol Stat. 18-471-493 doi:10. 1007/s10651-010-0147-7.

Pradhan B, Mansor S, Pirasteh S, Buchroithner MF (2011) Landslide hazard and risk analyses at a landslide prone catchment area using statistical based geospatial model. Int J Remote Sens 32(No. 14):4075-4087

Regmi NR, Giardino JR, Vitek JD (2010a) Modeling susceptibility to landslides using the weights of evidence approach: Western Colorado, USA. Geomorphology 115:172-187

Reneau SL, Dietrich WE (1987) The importance of hollows in debris flow studies; examples from Marin County, California. In: Costa, J.E., Wieczorek, G.F. (Eds.), Debris Flows/Avalanches: Process, Recognition, and Mitigation. Geological Society of America, Boulder, Colorado. Rev Eng Geol VII:165-180

Ruff M, Czurda K (2008) Landslide susceptibility analysis with a heuristic approach in the Eastern Alps (Vorarlberg, Austria). Geomorphology 94(2008):314-324

Temesgen B, Mohammed U, Korme T (2001) Natural Hazard Assessment Using GIS and Remote Sensing Methods, with Particular Reference to the Landslides in the Wondogenet Area, Ethiopia, Pergamon. Phys Chem Earth 26(No. 9):665-e

Terlien MTJ (1998) The determination of statistical and deterministic hydrological landslide-triggering thresholds. Environ Geol 35(2-3):124-130

Terlien MTJ, Van Westen CJ, Van Asch TWJ (1995) Deterministic modelling in GIS based landslide hazard assessment. In: Carrara A, Guzzetti F (eds) Geographical Information System in Assessing Natural Hazard. Kluwer Academic Publishers, Dordrecht pp 57-77

Van Westen CJ, Rengers N, Soeters R (2003) Use of geomorphological information inindirect landslide susceptibility assessment. Nat Hazards 30:399-419

Woldearegay K (2008) Characteristics of large-scale landslide triggered by heavy rainfall in Tarmaber area, Central Highlands of Ethiopia. Geophysical Research 10: , EGU2008-A-04506,2008, SRef - ID:1607-7962/gra/EGU2008-A-04506 EGU General Assembly 2008 